2004, 10, 3861-3870. [6] J. Nylen, S. Lidin, M. Andersson, B. B. Iversen, H. Lui, N. Newman, U. Haussermann, Chem. Mater., 2007, 19(4), 834-838.

[7] T. Caillat, J.-P. Fleurial, A. Borshchevsky, Nasatech Briefs, Feb 1999. [8] B. L. Pedersen, H. Birkedal, M. Nygren, P. T. Frederiksen, B. B. Iversen, Appl. Phys. Letters, 2006, 89(24), 242108 .

\section{MS17 O3}

Positive Electrode Materials Based On Moroccan Mineral Resources (Co, Mn, Ni) : Structural And Electrochemical Properties I. Saadoune ${ }^{1,} \mathrm{M}$. Aklalouch $^{1}$, M. Dahbi ${ }^{1}$, J.M. Amarilla ${ }^{2}, \mathrm{~K}$. Edstrom $^{3}$ And T. Gustafsson ${ }^{3}{ }^{1}$ ECME, LP2E2M, Université Cadi Ayyad, Morocco. ${ }^{2}$ ICMM CSIC, Madrid, Spain. 3 Angström Lab., Uppsala University, Sweden

\section{Keywords: Rietveld Refinement, Functionally graded Materials, Energy storage}

Intense research is worldwide devoted to the synthesis and characterization of positive electrode materials for lithium ion batteries owing to their high energy density and excellent power performances. Most of the efforts are concentrated on the two-dimensional layer-structure $\mathrm{LiMO}_{2}(\mathrm{M}: \mathrm{Co}, \mathrm{Mn}, \mathrm{Ni})$, the three-dimensional $\mathrm{LiMn}_{2} \mathrm{O}_{4}$ spinel and the $\mathrm{LiFePO}_{4}$ olivine type structure. Fortunately, Morocco produces cobalt, manganese, nickel and is the main phosphate producer in the world. For the layered $\mathrm{LiMO}_{2}$ oxide, $\mathrm{Li}^{+}$and $\mathrm{M}^{3+}$ cations are supposed to be orderly arranged along the (111) direction of the rock salt cubic lattice leading to a 2D layer structure, isostructural with $\alpha-\mathrm{NaFeO}_{2}$ (space group $\mathrm{R}-3 \mathrm{~m}$ ). $\mathrm{Li}^{+}$cations reside at Wyckoff $3 \mathrm{a}\left(\begin{array}{lll}0 & 0 & 0\end{array}\right)$ octahedral sites, $\mathrm{Ni}^{3+}$ cations are located in octahedral $3 b\left(\begin{array}{lll}0 & 0 & 1 / 2\end{array}\right)$ and oxygen anions are in a cubic close-packing, occupying the $6 \mathrm{c}\left(\begin{array}{lll}0 & 0 \mathrm{z}\end{array}\right)$ sites. Stoichiometric $\mathrm{LiNiO}_{2}(\mathrm{Li} / \mathrm{Ni}=1)$ is difficult to synthesize. Some extra-nickel ions are present in the $\mathrm{Li}$ plane leading to $\left[\mathrm{Li}_{1-\mathrm{z}} \mathrm{Ni}_{\mathrm{z}}\right]_{3 \mathrm{a}}[\mathrm{Ni}]_{3 \mathrm{~b}}\left[\mathrm{O}_{2}\right]_{6 \mathrm{c}}$ true formula. This results in a lower initial capacity as well as severe capacity loss upon cycling. Co substitution for Ni leads to strictly two-dimensional $\mathrm{LiNi}_{1-y} \mathrm{Co}_{\mathrm{y}} \mathrm{O}_{2}$ oxide without extra-nickel in the lithium plane. We have selected the $\mathrm{LiNi}_{0.7} \mathrm{Co}_{0.3} \mathrm{O}_{2}$ composition for the electrochemical study. In order to increase its electronic conductivity and to make easier the lithium diffusion during the intercalation process, two ways were chosen: i) synthesis by the combustion method which leads to small particle sizes, ii) substitution of $\mathrm{Mn}$ for $\mathrm{Ni}$ and $\mathrm{Co}$, which leads to the existence of mixed valence system. The results of structural study were discussed in relation with magnetic and electrochemical properties.

On the other hand, $\mathrm{LiMn}_{2} \mathrm{O}_{4}$ adopts the spinel structure

(space group $\mathrm{Fd} \overline{3} \mathrm{~m}$ ) consisting of a cubic close packed oxide ions with the manganese ions in one half of the octahedral site (16d wyckoff site) and $\mathrm{Li}^{+}$ions in oneeighth of tetrahedral sites (8a site). Although of its low coast and good environmental benignity, this oxide suffers from a serious capacity deterioration problem after cycling at high temperatures which seems to be related to the existence of Jahn-Teller $\mathrm{Mn}^{3+}$ ions. In order to improve the rate capability of the materials and to keep the oxidation state of manganese as $\mathrm{Mn}^{4+}$, we have carried out the synthesis of nanocrystalline double substituted spinels $\mathrm{LiNi}_{1.5-\mathrm{y}} \mathrm{Ni}_{0.5-\mathrm{y}} \mathrm{Cr}_{2 \mathrm{y}} \mathrm{O}_{4}$. The samples have been characterized at first by X-ray diffraction. The Scherrer method has been used to elucidate the thermal evolution of the average crystallite sizes. The relationship between the structural data and the electrochemical performances of the studied samples will be presented during the ECM meeting.

Acknowledgements: Many thanks to the French Foreign Ministry (MAE) for the financial support under the Corus program (contract no 02211 121)

\section{MS17 O4}

High-pressure structural studies of energetic compounds C. R. Pulham ${ }^{a}$ A. J. Davidson, ${ }^{a}$ I. D. H. Oswald, ${ }^{\text {a }}$ D. I. A. Millar, ${ }^{a}$ F. P. A. Fabbiani, ${ }^{\text {b }}$ D. J. Francis, ${ }^{\mathrm{b}}$ W. G. Marshall, ${ }^{\mathrm{b}}$ A. S. Cumming, ${ }^{\mathrm{c}}$ D. R. Allan, ${ }^{\mathrm{d}}$ A. R. Lennie ${ }^{\mathrm{e}}$ and T. J. Prior. ${ }^{\mathrm{e}}{ }^{\mathrm{a}}$ School of Chemistry and Centre for Science at Extreme Conditions, University of Edinburgh,UK. ' ${ }^{\mathrm{b}} I S I S$ Neutron Facility, Rutherford Appleton Laboratory,UK. ${ }^{\mathrm{c} D s t l,}$ Fort Halstead, Sevenoaks,UK. ${ }^{\mathrm{d}}$ Diamond Light Source, UK. ${ }^{e}$ SRS, Daresbury Laboratory, Warrington, UK

E-mail: C.R.Pulham@ed.ac.uk

Keywords: energetic materials, high-pressure diffraction, polymorphism

The effective modelling of the properties and performance of solid energetic materials (propellants and explosives) under operational conditions requires detailed knowledge of the crystal structures of these compounds. In many cases, the crystal structure of the compound obtained under ambient conditions is used as the basis for modelling properties at higher temperatures and pressures because structural information is often not available under more extreme conditions. However, such extreme conditions can lead to substantial changes in intermolecular interactions and molecular geometries, and can even induce phase transitions leading to dramatic changes in properties such as detonation velocity, shock sensitivity, and reactivity. There is therefore a requirement to obtain detailed structural information about these materials under extreme conditions. Using a combination of X-ray and neutron diffraction techniques, augmented by vibrational spectroscopy, we have studied a series of energetic ammonium salts and have obtained detailed structural information for these materials at pressures up to $\sim 8 \mathrm{GPa}$. Under hydrostatic conditions ammonium perchlorate undergoes a first order phase transition at $3.98 \mathrm{GPa}$ in agreement with the results of a previous study [1]. We have successfully solved and refined the structure of this new orthorhombic phase, which features a more close-packed structure with more extensive hydrogen bonding. Contrary to a previous report [2], no evidence was found for a pressure-induced phase transition in ammonium dinitramide up to $4.03 \mathrm{GPa}$ - an equation of state up to this pressure has been obtained. Significant changes were observed in the intermolecular contacts involving N-H...O-N interactions, and in the torsional angles of the dinitramide ion. We have also studied the effects of pressure on the widely used secondary explosives HMX and RDX. Structural information on the $\beta$-form of HMX up to $\sim 8 \mathrm{GPa}$ has been obtained. Neutron powder diffraction studies of RDX up to $\sim 8 \mathrm{GPa}$ confirm the previously observed $\alpha-\gamma$ transition at $\sim 4 \mathrm{GPa}[3,4]$ and suggest a significant conformational change in the high-pressure polymorph. 
[1] S.M. Peiris, G. I. Pangilinan, T. P. Russell, E. F. Westrum, Jr. and B. H. Justice, J. Phys. Chem. A. 2000, 104, 1118.

[2] T. P. Russell, G. J. Piermarini, S. Block and P. J. Miller, $J$. Phys. Chem., 1996, 100, 3248.

[3] P.J. Miller, S. Block and G. J. Piermarini, Combust. Flame, 1991, 83, 174 .

[4] N. Goto, H. Fujihisa, H. Yamawaki, K. Wakabayashi, Y. Nakayama, M. Yoshida and M. Koshi, J. Phys. Chem. B., 2006, $110,23655$.

\section{MS17 O5}

Magnetic and crystal structure of the $\mathrm{BiCrO}_{3}$ multiferroic compound. Pierre Bordet ${ }^{\mathrm{a}}$, Céline Darie ${ }^{\mathrm{a}}$, Céline Goujon ${ }^{\mathrm{a}}$, Maria Bacia ${ }^{\mathrm{a}}$, Holger Klein ${ }^{\mathrm{a}}$ and Emmanuelle Suard ${ }^{\mathrm{b}}$, a Institut Néel, CNRS-UJF, BP166, 38042 Grenoble cedex 9, France, ${ }^{\mathrm{b}}$ Institut LaueLangevin, BP156, 38042 Grenoble cedex 9, France E-mail: pierre.bordet@grenoble.cnrs.fr

\section{Keywords: multiferroics, perovskite, neutron} diffraction

Bi-based perovskites are the subject of a renewed research interest due to the coexistence of magnetic and electric orders observed in $\mathrm{BiMnO}_{3}$ and $\mathrm{BiFeO}_{3}$. This rare phenomenon is thought to originate from the structural distortion induced by the $6 \mathrm{~s}^{2}$ electron lone pairs of the $\mathrm{Bi}^{3+}$ cations. Another consequence is the instability of many of these compounds at room pressure. We report here the synthesis at high pressure and the crystallographic/magnetic investigation of $\mathrm{BiCrO}_{3}$, an up- to-now less studied material [1], using electron microscopy and temperature dependent $\mathrm{x}$-ray and neutron powder diffraction.

Polycrystalline samples of $\mathrm{BiCrO}_{3}$ were synthesized by high pressure solid state reaction in a Conac anvil-type apparatus at $2 \mathrm{GPa}$ and $750^{\circ} \mathrm{C}$. Magnetic susceptibility measurements show the onset of magnetic order at $114 \mathrm{~K}$ followed by a large increase below $80 \mathrm{~K}$. X-ray powder diffraction measurements were carried out up to $900^{\circ} \mathrm{C}$ under inert gas or air. Neutron powder diffractograms were collected on the D20 and D2B instruments of the ILL-Grenoble between $2 \mathrm{~K}$ and $470 \mathrm{~K} . \mathrm{BiCrO}_{3}$ is found to be isostructural to $\mathrm{BiMnO}_{3}$ at room temperature, with monoclinic space group $\mathrm{C} 2$, and 3 independent $\mathrm{Cr}^{3+}$ cation sites. It transforms to the orthorhombic $\mathrm{GdFeO} 3$ type at $405 \mathrm{~K}$. Although the observed magnetic neutron scattering is confined to the nuclear Bragg peaks, solution and refinement of the neutron diffraction data indicate the appearance of G-type anti-ferromagnetic order at the 114 $\mathrm{K}$ transition temperature, with all spins aligned along one of the unit cell axes, spins on different $\mathrm{Cr}$ sites being antiparallel. This is followed by a progressive spin reorientation between $80 \mathrm{~K}$ and $60 \mathrm{~K}$. The low temperature value of the magnetic moment is $2.5 \mu \mathrm{B}$ as expected for $\mathrm{Cr}^{3+}$ cations. Detailed results of these investigations and comparison with dielectric measurements will be presented at the meeting.

[1] Niitaka S. Et al.., Solid State Ionics 172 (2004) 557-559 